\title{
MARCA-PASSO ARTIFICIAL USADO NO \\ BLOQUEIO ATRIOVENTRICULAR
}

Zuleika M.Kannebley *

Introduçāo

Marca-passo artificial é um aparelho eletrô nico eapecial que permite controlar os batimentos cardíncos por meio de choques elétricos repetidos em intervalos regulares.

Para melhor compreensão dos fins a que se destina e do seu funcionamento é útil recorrer aos conhecimen tos anatomofisio'ógicos do sistema de transmissão de impulsos do coração. Eis a razāo pela qual iniciamos êste artigo evo cando aquêles conhecimentos básicos para fundamentar o assun to por nós escolnido.

Dentro do coração há um sistema de condụ ção de estímulos, responsável pelas contraçōes rítimicas e su cessivas dos átrios e ventrículos. Dêste sistema fazem parté as seguintes estruturas especializadas so nodo sino-atrial (S-A) implantado na parede do átrio direito, entre 08 orifícios de a bertura das veias cavas; o nodo atrioventricular (A-V) situado na parte inferior do septo interatrial próximo ao seio coroné rio; o fascículo atrioventricular (feixe de His') que se origina no nodo $A-V$, depois de descer curta distância, divide-se em dois ramos, um para cada ventrículo; êstes dois ramos vão terminar numa rêde de filamentos delicados (a rêde Purkinje) que se estende pela parede vetricular.

Normalmente o estímulo para a contração, ori ginado no nodoS-A (marca-passo do coraçāo), propaga-se pelas

* Professôra de Enfermagem Ciruirgica da Escola de Enfermagem de USP. 
fibras musculares dos átribal levando-os a se contrairem. Em seguida 0 nodo A-V recebe o estímulo, transmite-o para o fei xe de Bis e réde de Purkinje resultando a contração simiultânéa dos ventrículos. Nesta cadeia de transmissäo de impulso,o fei xe de Hị exerce funçāo muito importante por ser a única via pela qual o estimulo poderá alcançar os ventrículos.

Se eata vin fôt interrompida num ponto aci ma da bifurcafio daquele feire, dar-se-á um bloqueio cardía co completo ou bloqueio atrioventricular $A-V$ que se caracteriza por ume discociagäo de ritmos entre os átriois e ventrículos. Apesar dos impulsos nä conseguirem caminhar pelo feixe de His, on ventriculos sontinuan em atividade, e isto porque êles também têm a capacidade de gerar impalsos, embora em in tengidade menor do que 0 aodo S-A. O me se observa portanto no bloqueio A-V, é que o rttmo atrial mantém a freqliência nor mal em tôrno de 70 betimentos por minuto e 0 ritmo ventricu lar passa a ser de 30 a 40 por minuto.

Os pacientes com bloqueio A-V estio sujeI tos a apresentar crises de Stokes-Adams por isquemia cerebral. Sāo crises imprevisíveis de acentuados distúrbios do ritmo ven tricular que dificultam o furo sanguf́neo ao cérebro. A isque mila cerebral pode causar tonturas, desmaios, convulsōes, in coneciência e morte.

Um dos métodos modernos de tratamento dos pacientes que apresentam crises repetidas do síndrome StokesAdams, consiste na implantaçäo de um marca-passo artificial.

Diversas sāo as afeç̧ōes citadas como cau sas de bloqueio A-V adquirido, e entre elas estāo as miocardi tes, endocardites, arterioesclerose coronária e outras. Bm nosso país, a cardiopatia crônica chagásica é responsável por uma porcentagem relativamente alta de casos de bloqueio car diảco.

Queremos tavobém lembrar que a cirurgia in tracardíaca para correção de defeitos do septo interventricular. 
poderá provocar no paciente um bloqueio $A-V$ transitório em conseqtência do trauma cirúrgico sôbre o feixe de His ou estru turas que lhe são próximas. A comoressão do feixe por hema toma ou edema explica o aparecimento dêste tipo de bloqueio transitório em certo número de pacientes operados. Nestes casos, o cirurgiāo lança māo de um marca-passo artificial que será colocado no paciente.

Métodos para Uso do Marca.-Passo

Na literatura especializada encontramos di versos métodos de emprégo dos marca-passos eletrônicos, uns de uso transitório (marca-passo externo), oxtros para uso per manente (marca-passo interno). Ëntre êstes últimos encontra mos ainda implentaçāo em zonas diferentes ( axilar e abdomi nal). Há ainda a considerar 08 marca-passos cujos elétrodos säo introduzidos pela via venosa.

Marca-Passo Externo

Desejamos focalizar inicialmente um mar ca-passo externo usado na 12. Clínica Cirúrgica do Bospital das Clínicas da Faculdade de Medicina da Universidade de Säo Paulo, por ser o tipo que temos tido oportunidade de observar em fun cionamento com pacientes que, submetidos a uma cirurgia in tracardíaca, aprecentam um bloquelo A-V transitório.

O aparelho, de fabricaçāo americana (Med tronic Inc.), consta de uma fonte geradora de estímulos elétri cos e flos metálicos que conduzem a corrente para os elétrodos implantados, um no miocárdio do ventrículo direito e outro no tecido celular sub-cutâneo da regiāo torácica anterior cnmo te mos visto (Fig. 1), ou em outra área do corpo. 


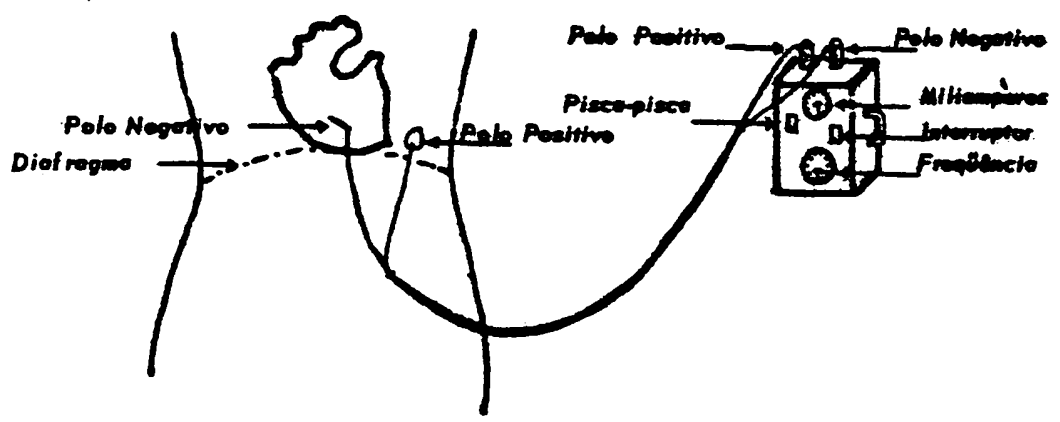

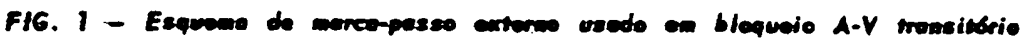

O marca-passo, lonte geradora de energia, é uma pequena caixa de materin plástico com as dimensōes de $10 \times 6 \times 2,5 \mathrm{~cm}$ que contém um conjunto transistorizado alimen tado por uma pilha de mercúrio. Quando em funcionamento, 0 aparelho emite choques elétricos intermitentes, reguláveis de 1,5 a 20 millamperes, que controlam o ritmo cardíco na fre qtîncis desejada. Na face anterior do marca-passo, observam-se dois pequenos mostradores de relógio com ponteiro móvel. Um deles serve para graduar a amperagem, bastando para isto fazer girar o pouteiro para o número de mninmpéres que se de seja usar. O segundo:mostrador permite graduar a frequência dos estímulos. Uma pequena luz que acende e apaga (pisca-pis ca) indica os estfmulos do marca-passo, podendo contar-se a frequếncia pelo acender dn lîmpada.

Os elétrodos año flos de aço inoxidável mul tifilamentados que ve comunicam com o marca-passo através de flos do mermo material. On flos sāo reveatidos de material 18olante, exceto no pequeno percurso em que são implantados no tecidos. O elétrodo de pólo negativo tem na sua extremida de uma pequena agulha de sutura para facilitar a introduçāo no miocárdio. Uma vez tranafirado o tecido e prêso o elétrodo com fio de suture, a agulh é cortada e retirada pelo cirirgião. 
O elétrodo de pólo positivo tem na extremidade uma placa de metal que é implantada no tecido celular sub-cutôneo da área escolhida pelo operador.

Os fios metálicos, suficientemente longos $(3,5 \mathrm{~m})$, permitem sua fixação em voltas circulares sôbre o tó rax e a livre movimentação do paciente no leito. Convém lem brar que a caixa do marca-passo, como temos observado é fixa da na guarda da cabeceira da cama; se os fios forem curtos po derāo desprender-se aos movimentos e esforços do paciente.

Acompanhando a evolução do paciente no pós -operatório e auxiliado pelos resultados do el etrocardiograma, compete ao cirurgiāo decidir sobre a retirada do marca-passo. Como medida de segurança, a retirada definitiva é precedida de interrupçōes temporárias da emissão da corrente, bastando pa ra isto desligar do marca-passo os dois fios dos elétrodos. Es tando o paciente em condiçōes de deambular e tendo regredido completamente o bloqueio, os fios dos elétrodos, que ficam ex ternamente ao tórax, são desligados dos elétrodos internos.

O elétrodo miocárdico só deverá ser retira do após aproximadamente três semanas, quando então as aderên cias resultantes da pericardite pós-operatória impedirão o apá recimento do tamponamento cardíaco por hemorragia no local de desgarro. Para proceder a retirada, o cirurgião puxa deli cadamente o elétrodo, e caso êste ofereça resistência para se desprender livremente, será cortado no ponto em que foi possí vel exteriorizá-lo, deixando-se no paciente, e sem tnconvenien tes, a porção restante. O el étrodo de pólo positivo por estar no tecido sub-cutáneo é retirado com facilidade.

Existe um outro tipo de marca-passo externo que não exigindo nenhuma incisāo cirúrgica tem sido usado em ca so de emergência em súbito bloqueio. Os elétrodos sāo colocados diretamente sobre a pele da regiāotorácica anterior sendo fixa dos por uma faixa de borracha que circunda o tórax. Este méto do, entretanto, tem incovenientes que restringem seu largo emprê go: para que os impulsos cheguem ao coraçāo, estando o tórax fe chado, há necessidade de se empregar correntes de intensidade 
elevada, com o perigo de provocar queimaduras na pele do pa ciente; acrescido de que 08 impulsos provocam contraçöes mus culares dolorosas. Deve-se proteger a pele, sob os elétrodos, com nma pasta especia, removida e substituída cada duas ou três horas, e fazer diàriamente a mudança da posiçāo dos elé trodos.

Marca-Passo Interno

NorOs e várlos tipos de marca-passos foram idealizados e introduzidos na terapêtica médico-cirúrgica, co mo recursos auxiliares na assisténcia aos pacientes necessita dos de um tratamento longo e permanente uu bloqueio cardíaco.

Para êstes pacientes tem sido usado o mé todo de marca-passo implantado no tecido subcutâneo da regiāo abdominal ou arilar.

Um pequeno aparelho contendo o conjunto transistorizado com micropilhas de mercúrio ligadas em série é implantado, segundo a preferéncia do cirurgiāo, numa daque las áreas. O aparelho acha-se envolvido por uma capa de bor racha de sllicone que é um material bem tolerado pelos tecidos.

Os condutores da corrente elétrica säo dois fios metálicos 11 gados 20 marca-passo. São revestidos de ma terial Lsolante exceto nas extremidades opostas e finils. Estas pequenas porçōes, nāo revestidas, sāo 08 reais elétrodos que implantados diretamente no mlocárdio estimulam a contração ventricular.

A colocaçāo dêste tipo de marca-passo na parede abdominal exige uma toracotomia anterior esquerda a fim de expor o coraçāo, abrir o pericárdio e introduzir os elé trodos no miocárdio, e uma incisāo abdominal para preparo de uma bôlsa subcutânea onde será colocado o marca-passo. Com 
uma pinça longa, o cirurgiāo abrirá, no tecido subcutâneo da parede abdominal, um túnel ligando a incisāo torácica à área abdominal escolhida. Os fios dos elétrodos sāo passados atra vés do túnel em direçāo ao coraçāo; o marca-passo, já prepa rado com as pilhas e os fios metálicos ligados, é introduzido na bôlsa subcutânea do abdome.

Se o cirurgiāo preferir implantação axilar, - método é, em linhas gerais, o mesmo usado para implanta ção abdominal sendo a bôlsa subcutânea preparada na regiāo a xilar esquerda e o túnel dissecado da incisão tórácica à axila.

As pilhas de mercúrio do aparelho têm a du raçāo média de 5 anos e devem ser trocadas em tempo hábil, antes que pelo seu desgaste venham a prejudicar a estimulação elétrica do coraçāo. Executando uma pequena incisāo cirúrgi ca sôbre o local da implantaçāo do marca-passo o cirurgiāo fa rá a troca das pilhas ou do marca-passo se necessário. Os elé trodos do miocárdio sāo fabricados para uBo indefinido evitando assim nova toracotomia.

A infeç̧ão e a reação alérgica devem ser lembradas como possíveis complicaçōes dos marca-passos in ternos: a primeira pela introduçāo de germes decorrente de uma falha na esterilizaçāo do material, e a segunda pela rea ção dos tecidos ao corpo estranho. A infecção, uma vez insta lada, segue o trajeto dos fios prejudicando o funcionamento do aparelho e via de regra nāo regride enquanto o corpo estranho nāo fốr removido. Frente a esta situação compete ao cirurgiāo escol her um nôvo método para corrigir o bloqueio do paciente.

A esterilização do material a ser implanta do deve ser muito criteriosa a fim de evitar a infeçào. São in dicados os vapôres de Paraformaldeido durante 18 horas,no mí nfmo, para o material que se danifica em altas temperaturas e umidade.

A educaçāo do paciente para a alta deve in cluir esclarecimentos para que procure o hospital ou o médico, 
caso venha a apresentar febre, dor ou tumelaçäo em qualquer ponto de implantaçāo do aparelbo.

Marca-Passocom Elétrodos Intravenosos

Outra técnica de colocaçāo dos elétrodos, consiste as introduçāo de um cateter elétrodo por uma vein até atingir o endochirdio do ventrículo direito e portanto näo exige uma toracotomia. Existem dols tipos de cateter elétrodo. Um dêles é de uso temporário e é ligado a um marca-passo exter no. O outro é revestido com borracha de silicone e é de uso permanente, Bendo empregado com o marca-pas:o implantável. Como via de entrada do cateter tem sido usada, de preferência, a vein jugular.

Por êste método de elétrodo intravenoso, consegue-se a estimulaçāo cardĺca desejada pelo emprégo de corrente de batra intensidade, inferior à exigida por outros mé todos. Isto é vantajoso considerando-se que os choques elétrí cos de voltagem elevada produzem sensą̧ão desagradável ao pa ciente e contraçöes dolorosas.

Marea-Pasoos Fabricados em São Paulo

No Instituto de Cardiologia do Estado de Sāo Paulo está sendo produzido um modêlo de marca-passo externo - outro de marca-paseo implantável com elétrodos epimlocárdi cos e com elétrodos Intravenosos*.

* Irformaçōes fornecidas pelo Dr. Adib Jatene,Diretor do Servi ço de Experimentação e Pesquisas daquele Instituto. 


\section{Conclueño}

Nōotivemos a pretensāo de incluir neste tra ballo, todos os métodos de marca-passos eletrônicos porque constantemente enrcem novas idäins, novas experiêncins que levam os cirurgióes a uearem novos e mais aperielgondos ape relbos.

Foi nosso intuito conjugar as informaçōes colhidas em concultas de livros e revistas com as nossas experiênctas e observaçöes no culdado pós operatório de pacientes submetidos a cirurgie intrecerdíce na 1a. Clínica Cirúrgica do Hospital das Clínicas de São Paulo.

Como enfermeiras, estamos certas de que a qualidade de nossos cuidados de enfermagem só poderá ser e ficlente se pudermos sempre encontrar motivação para estu dar e compreender em bases científicas, qualquer nôvo recur 80 introduzido ne terapética moderna aplicada aos pacientes a nós confindos,

Referências Blblioğráticas

1. BEST, C.H.|e outros | - Fementos de Fisiologia Humana.

2a. ed. rev. São Panlo, Renascença, 1950. p.102-104116.

2. BUSBY, E.R. - Artificial cardiac pacing. Nureing Mirror and Mldwives Journal, $118(3104): 4-6$. Dec. 1964.

9. CORRAA, A. Netto - Clínica Cirúrgica. São Panlo, Pro cienx 1966, $\vee .3$, p. 18.

4. ERHART, E.A. - Elementos de Anatomin Humana. 2a.ed.

Sâo Pawlo, Athenea 1965, p. 168. 
5. HELLER, A. F. - Nursing the patient with an artificial pace maker. The American Journal of Nursing, $64(4): 87$ 92 Apr11, 1864.

6. PRADO, F. Cintra | outros| - Atualizaçāo terapêtica. 6a. ed. Sño Paulo, Artes Médicas, 1866. p.217-219.

7. SHAFER, K. N. |and others|-Medical surgical nurBing. 3rd ed. Saint Louls, Mosby, 1964. p.252-255.

8. SUTTON, A. L. - Bedside nursing tecniques in medicine and surgery. Phlladelphin, Seunders 1964. p.222. so usado no bloqueio atrioventri cular. Revista da Escola de Enfermagem da USP, 1(1):49-58, out. 1967 . 